\title{
Volumetric Properties of Binary Mixtures of 1-Ethyl-3-methylimidazolium ethyl phosphonate + Methanol or 2-Propanol
}

\author{
Farida Allal $^{\mathrm{a} *}$, Abdellah Dahmani ${ }^{\mathrm{b}}$, Boubaker Saidat $^{\mathrm{a}}$
}

\begin{abstract}
a'Laboratoire Physico-Chimie des Materiaux Laghouat University, Post Office Box 32G, Laghouat 03000, Algeria. ${ }^{b}$ Laboratoire de Thermodynamique et de Modelisation Moleculaire, Faculte de chimie, USTHB, BP 32 El-Alia, BabEzzouar, Algiers, Algeria e-mail: faridaallal@gmail.com
\end{abstract}

Received 25 February 2019, Revised 03 April 2019, Accepted 20 June 2019

\begin{abstract}
The present study aimed to determine the refractive indices at $293.15 \mathrm{~K}$ and density data at $\mathrm{T}=(283.15,293.15,303.15$ and 313.15) $\mathrm{K}$ of the binary mixtures of 1-ethyl-3-methylimidazolium ethylphosphonate + methanol or 2-propanol under the atmospheric pressure. The excess molar volume, the apparent molar volume, the partial molar and excess partial molar volumes of the components at infinite dilution were calculated from the experimental values. The results of excess molar volumes were fitted to a Redlich- Kister equation, leading thus to obtain the coefficients and to estimate the standard deviations between the experimental and the calculated quantities. The results of excess molar volumes of the two investigated binary mixtures showed negative deviations from ideal behavior of the investigated binary systems which can be then discussed in terms of ion-dipole interactions, formation of hydrogen bonds and structural factors. Additionally, the refractive indices measurements and the deviations of refractive index were determined.
\end{abstract}

Keywords: Ethylimidazolium ionic liquid; density; refractive index; excess volumes; volumetric properties.

\section{Introduction}

Ionic liquids (ILs) are classified as an important compound widely used in the industry [1-6], as well as they mainly represent an interesting family of molecules used in separation processes, including extractive distillation, liquidliquid extraction, catalysis, synthesis and electrochemistry [7-13]. Moreover, ionic liquids can be efficiently used as alternative solvents for conventional volatile organic solvents due to their typical characteristics (negligible vapor pressure at room temperature, no flammability, wide liquid range and thermal stability at high temperatures). Thermodynamic properties of ILs mixtures (phase equilibrium data, activity coefficients at infinite dilution, excess molar volumes and heat capacity) provide better understanding about the molecular interactions occurring in a liquid solution. Although such studies are also important for the test and the development of theories and models.

The volumetric properties, especially densities were proved to be useful for the understanding of the interactions; solute-solute and solute-solvent, as well as for the design of industrial processes [14-19]. Imidazolium-based ILs are mostly used in separation processes [20-23], and considered as the best extractants for a large number of organic and inorganic solutes [24-27]. Hence, several studies have investigated the thermodynamic properties of binary mixtures of imidazolium- based ionic liquids, especially the volumetric properties. The properties of the solubility parameters of [EMIM] Ac + ethanol and [EMIM]Cl + ethanol mixtures have been determined by Dickmann et al [28]. Also, Matkowska and Hofman [29] determined the volumetric properties of [C6mim][MeSO4], [C6mim] [EtSO4] and $\left[\mathrm{C}_{4} \mathrm{mim}\right]\left[\mathrm{EtSO}_{4}\right]$ with methanol or ethanol. The acoustic, volumetric and osmotic properties of 1-butyl-3-methylimidazolium dicynamide associated with primary and secondary alcohols were estimated as described elsewhere [30]. In this context, Deng et al. [31] also determined the volumetric properties, and the enthalpies of binary mixtures of 1-alkyl-3-methylimidazolium bis (trifluoromethylsulfonyl) imide [ $\left.\mathrm{C}_{\mathrm{n}} \mathrm{MIM}\right][\mathrm{NTf2}]$ with alcohols \}, as well as the volumetric properties of 1-butyl-3methylimidazolium methyl sulfate ([BMIM] $\left[\mathrm{MeSO}_{4}\right]$ with methanol or ethanol or 1-propanol or nitromethane)\} were determined by Deenadayalu et al. [32]. In addition, the excess molar volumes of $[\mathrm{BMIM}]\left[\mathrm{CH}_{3} \mathrm{SO}_{4}\right]$ and [BMIM] $\left[\mathrm{OcSO}_{4}\right]$ with alcohols at $298.15 \mathrm{~K}$ and ambient pressure were determined as previously reported [33]. Importantly, ILs-based on alkylphosphonate anions were found to be able to extract carbohydrates and cellulose from biomass [34], On top of that, the activity coefficients at infinite dilution of various solutes in ionic liquids based on alkylphosphonate anions were measured by using gas-liquid chromatography, providing therefore, detailed knowledge about the intermolecular interactions between ILs and organic solutes [35-39].

In our previous work [40], the activity coefficients at infinite dilution $\gamma_{12}^{\infty}$ for the selected organic solutes of 1ethyl-3-methylimidazolium ethylphosphonate [EMIM] $\left[(\mathrm{EtO})(\mathrm{H}) \mathrm{PO}_{2}\right]$, with temperature values ranged from 323.15 to $363.15 \mathrm{~K}$. were measured using gas-liquid chromatography. The results showed potentiality of 1-ethyl3-methylimidazolium ethylphosphonate for separation process applications, especially for the separation of sulphur and nitrogen compounds from aliphatic hydrocarbons. In spite of their importance, ILs-based on alkylphosphonate anions are poorly elucidated. Therefore, the study was 
designed to investigate the densities of binary mixtures of 1ethyl-3-methylimidazolium ethylphosphonate + methanol, or 2- propanol at four temperature values ranging between 283.15 and $313.15 \mathrm{~K}$, and hence the excess molar volumes, apparent molar volumes, partial and excess molar volumes at infinite dilution can be calculated.

\section{Materials \& Methods}

\subsection{Chemicals}

Methanol and 2-propanol were purchased from Sigma Aldrich with more than $99.5 \%$ of purity and were used in the experiments without further purification, since 1-ethyl-3methyl imidazolium ethylphosphonate[EMIM] [(EtO) (H) $\mathrm{PO}_{2}$ ] was purchased from Solvionic with a purity of $98 \%$ by mass. The ionic liquid was dried for more than $24 \mathrm{~h}$ at $T=323.15 \mathrm{~K}$ under reduced pressure to remove volatile impurities and trace of water.

\subsection{Experimental Design}

\subsubsection{Density Measurements}

The densities $\rho$ were measured by using a vibratingtube digital densimeter (Model DMA5000, Anton Paar. The temperature in the cell was monitored through a digital thermometer with an accuracy of $0.01 \mathrm{~K}$. Calibrations of the apparatus were periodically performed with the ultrapure water and dry air. The uncertainties in the temperature and density measurements were estimated to be within $\mp 0.01 \mathrm{~K}$ and $\mp 4.10^{-5} \mathrm{~g} \cdot \mathrm{cm}^{-3}$, respectively. In this work, the estimated experimental densities of pure 1-ethyl-3methylimidazolium ethylphosphonate, methanol and 2propanol at various temperatures and literature comparisons are shown in Table 1 [41-45]. The mole fraction of each mixture was obtained from the measured apparent masses of the components, meanwhile an electronic analytical balance with an accuracy of $\pm 1 \times 10^{-4}$ $\mathrm{g}$ was used for weighing chemicals and compounds.

Table 1. Density $\rho$ of Pure Liquids with the Available Corresponding Literature Values at Different Temperatures and Atmospheric Pressure.

\begin{tabular}{|c|c|c|c|c|}
\hline \multirow[b]{2}{*}{ Reference } & \multicolumn{4}{|c|}{ Temperature (K) } \\
\hline & 283.15 & 293.15 & 303.15 & 313.15 \\
\hline & \multicolumn{4}{|c|}{$\rho\left(\right.$ g.cm $\left.^{-3}\right)$ for $[\mathrm{EMIM}]\left[(\mathrm{EtO})(\mathrm{H}) \mathrm{PO}_{2}\right]$} \\
\hline This study & 1.15618 & 1.1508 & 1.14659 & 1.1434 \\
\hline Allal et al [40] & - & 1.1503 & - & 1.1439 \\
\hline & \multicolumn{4}{|c|}{$\rho\left(\right.$ g.cm $\left.{ }^{-3}\right)$ for methanol } \\
\hline This study & 0.80112 & 0.79151 & 0.78208 & 0.77257 \\
\hline K-S.Kim et al [41] & 0.80211 & 0.79298 & 0.78350 & 0.77401 \\
\hline Q.Yang et al [42] & - & 0.79130 & 0.78186 & 0.77233 \\
\hline G.Gonfa et al [43] & - & 0.79165 & 0.78224 & 0.77272 \\
\hline \multirow[t]{2}{*}{ C.Yang et al [44] } & - & 0.79154 & 0.78212 & 0.77260 \\
\hline & \multicolumn{4}{|c|}{$\rho\left(\mathrm{g}_{\mathrm{cm}} \mathrm{cm}^{-3}\right)$ for 2-Propanol } \\
\hline This study & 0.79354 & 0.78650 & 0.78002 & 0.77388 \\
\hline K-S.Kim et al [41] & 0.79336 & 0.78517 & 0.77665 & 0.76786 \\
\hline F.M.Pang et al [45] & 0.78535 & 0.78110 & 0.77712 & 0.76879 \\
\hline
\end{tabular}

\subsubsection{Refractive Index Measurements}

The refractive indices of pure liquids and their binary mixtures over the whole composition range at $293.15 \mathrm{~K}$ were measured by a digital refractometer (Krüss DR6000-T,). The uncertainties in the temperature and refractive index measurements were estimated to be within $\mp 0.02 \mathrm{~K}$ and $\mp 4.10^{-4}$, respectively. The calibration was checked for pure liquids with a known refractive index.

\section{Results and Discussion 3.1 Density}

Experimental densities under atmospheric pressure for the binary systems of [EMIM] $\left[(\mathrm{EtO})(\mathrm{H}) \mathrm{PO}_{2}\right](1)+$ methanol (2) or 2-propanol (2) were measured at a temperature ranging from 283.15 to $313.15 \mathrm{~K}$, and at intervals of $10 \mathrm{~K}$. The density data are listed in table 2, and are displayed in Figures $1 \& 2$. It appears that the density values increase with the increasing of $[\mathrm{EMIM}]\left[(\mathrm{EtO})(\mathrm{H}) \mathrm{PO}_{2}\right]$ concentration in binary solutions over the whole concentration range. Whilst, the density values decrease with the increment of temperature at the same composition.

Table 2. Experimental Densities for the Two Investigated Binary Mixtures at Temperature from $283.15 \mathrm{~K}$ to $313.15 \mathrm{~K}$ and under Atmospheric Pressure.

\begin{tabular}{ccccc}
\hline $\boldsymbol{X}_{\mathbf{1}}$ & $\mathbf{2 8 3 . 1 5}$ & $\mathbf{2 9 3 . 1 5}$ & $\mathbf{3 0 3 . 1 5}$ & $\mathbf{3 1 3 . 1 5}$ \\
\hline \multicolumn{5}{c}{$\left.\mathbf{\rho}(\mathbf{g . c m})^{-3}\right)$} \\
{$[\mathrm{EMIM}]\left[(\mathrm{EtO})\left(\mathrm{H}^{\mathrm{P}} \mathrm{PO}_{2}\right](1)+\right.$ methanol $(2)$} \\
0.0000 & 0.801120 & 0.791510 & 0.782080 & 0.772570 \\
0.0983 & 0.941023 & 0.934212 & 0.928372 & 0.923304 \\
0.2007 & 1.010851 & 1.004558 & 0.999329 & 0.994959 \\
0.2879 & 1.049151 & 1.043088 & 1.038141 & 1.020066 \\
0.4138 & 1.085544 & 1.079693 & 1.075012 & 1.071281 \\
0.5006 & 1.103341 & 1.098232 & 1.933439 & 1.089613 \\
0.6015 & 1.119718 & 1.114079 & 1.109659 & 1.106246 \\
0.6988 & 1.131750 & 1.126612 & 1.123307 & 1.119121 \\
0.7501 & 1.136082 & 1.142434 & 1.138227 & 1.132984 \\
0.8973 & 1.147923 & 1.142431 & 1.138232 & 1.135079 \\
1.0000 & 1.156180 & 1.150850 & 1.146590 & 1.143490 \\
{$[\mathrm{EMIM}]\left[(\mathrm{EtO})(\mathrm{H}) \mathrm{PO}_{2}\right](1)+2-$ propanol $(2)$} & & \\
0.0000 & 0.793540 & 0.786500 & 0.780020 & 0.773880 \\
0.0887 & 0.874419 & 0.870958 & 0.865790 & 0.858881 \\
0.1998 & 0.936920 & 0.930850 & 0.925698 & 0.921262 \\
0.3016 & 0.986550 & 0.980670 & 0.975790 & 0.971723 \\
0.4052 & 1.026470 & 1.020880 & 1.016202 & 1.012413 \\
0.5027 & 1.057453 & 1.051782 & 1.047244 & 1.043633 \\
0.6014 & 1.083452 & 1.077827 & 1.073376 & 1.069873 \\
0.7126 & 1.109578 & 1.102670 & 1.095771 & 1.088862 \\
0.8094 & 1.135471 & 1.128563 & 1.118472 & 1.111569 \\
0.8997 & 1.141714 & 1.136223 & 1.131093 & 1.128774 \\
1.0000 & 1.156180 & 1.150850 & 1.146590 & 1.143490 \\
\hline
\end{tabular}

Standard uncertainties $(\mathrm{u}): \mathrm{u}(\mathrm{T})= \pm 0.01 \mathrm{~K} ; \mathrm{u}(\rho)= \pm 4.10^{-}$ ${ }^{5} \mathrm{~g} . \mathrm{cm}^{-3}$

\subsection{Excess Molar Volume}

The excess molar volume $V_{m}^{E}$, was calculated by measuring the density according to the following equation:

$V_{m}^{E}=\left(x_{1} M_{1}+x_{2} M_{2} / \rho\right)-\left(\frac{X_{1} M_{1}}{\rho_{1}}+\frac{X_{2} M_{2}}{\rho_{2}}\right)$

where $\rho$ is the density of mixture, since $x_{1}, \rho_{1}, M_{1}, X_{2}, \rho_{2}$, and $M_{2}$ indicate, respectively the mole fractions, densities, and molecular weights of pure $[\mathrm{EMIM}]\left[(\mathrm{EtO})(\mathrm{H}) \mathrm{PO}_{2}\right]$ and pure methanol, or 2-propanol. The results of $V_{m}^{E}$ are shown in Table 3, and the dependence of $V_{m}^{E}$ on various temperatures is indicated in Figures 3 and 4.

The excess molar volume is correlated by a Redlich-

Kister type polynomial [46]:

$\frac{V_{m}^{E}}{\mathrm{~cm}^{3} \mathrm{~mol}^{-1}}=x_{1} x_{2} \sum_{i=0}^{n} A_{i}\left(2 x_{1}-1\right)^{i}$

where $x_{1}$ is the mole fraction of [EMIM] [(EtO) $\left.(\mathrm{H}) \mathrm{PO}_{2}\right], x_{2}$ is the mole fraction of methanol or 2-propanol, and $A_{i}$ denotes the polynomial coefficient. The standard deviation values between the calculated and the experimental data are given by the following equation:

$\sigma_{V_{m}^{E}}=\left[\sum \frac{\left(V_{\text {exp }}^{E}-V_{c a l}^{E}\right)^{2}}{(N-m)}\right]^{\frac{1}{2}}$

where $\mathrm{N}$ and $\mathrm{m}$ are the number of experimental points and the number of coefficients used in fitting the data, respectively. The values of fitted parameters and the standard 
deviations of the studied binary mixtures are shown in Table 4.

As seen in Figures 3 and 4, the $V_{m}^{\mathrm{E}}$ values are negative at all the investigated temperatures and in the whole composition range with a minimum value of $-1.2694 \mathrm{~cm}^{3}$. $\mathrm{mol}^{-1}$ at $\mathrm{x}_{\mathrm{IL}} \approx 0.2$ for the mixture [EMIM] $\left.(\mathrm{EtO})(\mathrm{H}) \mathrm{PO}_{2}\right](1)+$ methanol (2) and $-0.5637 \mathrm{~cm}^{3} \cdot \mathrm{mol}^{-1}$ at $\mathrm{x}_{\mathrm{IL}} \approx 0.4$ for the [EMIM][(EtO)(H)PO $\mathrm{PO}_{2}$ (1) + 2-propanol (2)] system at $\mathrm{T}=293.15 \mathrm{~K}$. The negative values of $\mathrm{V}_{\mathrm{m}}^{\mathrm{E}}$ indicate the existence of a volume contraction on mixing IL with alcohol due to the dominant electrostatic attraction between cation and anion found in IL, and hydrogen bonding between IL and molecular liquids. The interactions between ions and alcohol molecules are stronger than those found in the pure compounds, and this is in line with the results obtained for imidazolium based ILs by Vercher et al \& Sandhya et al. [4750]. The values of excess molar volumes decrease with the increase of the chain length of the alcohols. This trends in $\mathrm{V}_{\mathrm{m}}^{\mathrm{E}}$, attributing is attributed to the molecular interactions and packing effects, which decrease with the increase of the alcohol chain length. These results concord with those reported by Domanska et al. [33], Vercher et al. [51] and SanjaBelic et al. [52]. On the other hand, the molar volume of $[\mathrm{EMIM}]\left[(\mathrm{EtO})(\mathrm{H}) \mathrm{PO}_{2}\right]$ is $191.3462 \mathrm{~cm}^{3} \cdot \mathrm{mol}^{-1}$ at $\mathrm{T}=293.15 \mathrm{~K}$, a much larger value than that obtained for alcohols $\left(\mathrm{V}_{\mathrm{M} \text {,methanol }}=40.4795 \mathrm{~cm}^{3} \cdot \mathrm{mol}^{-1} \mathrm{~V}_{\mathrm{M} 2 \text {-Propanol }}=76.4093\right.$ $\left.\mathrm{cm}^{3} \cdot \mathrm{mol}^{-1}\right)$, and consequently the methanol molecules become easy to accommodate in the interstices of [EMIM] [(EtO) $\left.(\mathrm{H}) \mathrm{PO}_{2}\right]$. Also, the excess molar volume at the same composition becomes more negative when the temperature increases, and this is in accordance with [53].

Table 3. Excess Molar Volumes for the Investigated Binary Mixtures at Temperature from $283.15 \mathrm{~K}$ to $313.15 \mathrm{~K}$ and under Atmospheric Pressure.

\begin{tabular}{|c|c|c|c|c|}
\hline \multicolumn{5}{|c|}{ Temperature (K) } \\
\hline $\mathbf{x}_{1}$ & 283.15 & 293.15 & 303.15 & 313.15 \\
\hline \multicolumn{5}{|c|}{$V_{m}^{E}\left(\mathrm{~cm}^{3} \cdot \mathrm{mol}^{-1}\right)$} \\
\hline \multicolumn{5}{|c|}{$[\mathrm{EMIM}]\left[(\mathrm{EtO})(\mathrm{H}) \mathrm{PO}_{2}\right](1)+$ methanol (2) } \\
\hline 0.0983 & -1.0824 & -1.2155 & -1.3852 & -1.5925 \\
\hline 0.2007 & -1.1367 & -1.2694 & -1.4385 & -1.6392 \\
\hline 0.2879 & -1.1389 & -1.2612 & -1.4194 & -1.5607 \\
\hline 0.4138 & -1.0142 & -1.1155 & -1.2523 & -1.3496 \\
\hline 0.5006 & -0.9045 & -1.0569 & -1.1419 & -1.2593 \\
\hline 0.6015 & -0.8076 & -0.8757 & -0.9785 & -1.0885 \\
\hline 0.6988 & -0.6458 & -0.7495 & -0.8392 & -0.9358 \\
\hline 0.8059 & -0.5215 & -0.6044 & -0.6804 & -0.7632 \\
\hline 0.8973 & -0.0115 & -0.0127 & -0.0505 & -0.0798 \\
\hline \multicolumn{5}{|c|}{$[\mathrm{EMIM}]\left[(\mathrm{EtO})(\mathrm{H}) \mathrm{PO}_{2}\right](1)+2-\operatorname{propanol}(2)$} \\
\hline 0.0878 & -0.1535 & -0.1956 & -0.2417 & -0.2877 \\
\hline 0.1998 & -0.3687 & -0.4458 & -0.5456 & -0.6597 \\
\hline 0.3016 & -0.4684 & -0.5500 & -0.6540 & -0.7728 \\
\hline 0.4052 & -0.4908 & -0.5637 & -0.6657 & -0.7798 \\
\hline 0.5027 & -0.4600 & -0.5240 & -0.6175 & -0.7184 \\
\hline 0.6014 & -0.3887 & -0.4363 & -0.5150 & -0.5943 \\
\hline 0.7126 & -0.2981 & -0.3525 & -0.3972 & -0.4471 \\
\hline 0.8094 & -0.2210 & -0.2364 & -0.2939 & -0.3131 \\
\hline 0.8997 & -0.1457 & -0.1437 & -0.1708 & -0.1900 \\
\hline
\end{tabular}

\subsection{Apparent Molar Volume}

The apparent molar volume, $\mathrm{V}_{\phi \mathrm{i}}$, was calculated according to the following equation:

$\mathrm{V}_{\varphi 1}=\left(\mathrm{V}-\mathrm{x}_{2} \mathrm{~V}_{2}^{0} / \mathrm{x}_{1}\right)$

$\mathrm{V}_{\varphi 2}=\left(\mathrm{V}-\mathrm{x}_{1} \mathrm{~V}_{1}^{0} / \mathrm{x}_{2}\right)$

where subscripts 1,2 refer, respectively, to the ionic liquid and alcohol; $\mathrm{V}_{1}^{0}$ and $\mathrm{V}_{2}^{0}$ are the molar volumes determined from the experimental densities, and $\mathrm{V}$ is the molar volume of the solution determined by the following equation:
Table 4. The Values of Redlich-Kister Coefficients for the Studied Binary Mixtures of at Various Temperatures and at under the Atmospheric Pressure.

\begin{tabular}{|c|c|c|c|c|}
\hline \multirow{2}{*}{$\begin{array}{l}\text { Redlich } \\
\text { Kister } \\
\text { coefficients }\end{array}$} & \multicolumn{4}{|c|}{ Temperature $(\mathrm{K})$} \\
\hline & 283.15 & 293.15 & 303.15 & 313.15 \\
\hline \multicolumn{5}{|c|}{ [EMIM][(EtO)(H)PO2](1)+ methanol(2) } \\
\hline $\mathrm{A}_{0}$ & -3.8917 & -4.2570 & -4.7674 & -5.3382 \\
\hline $\mathrm{A}_{1}$ & 2.1022 & 2.4417 & 2.7944 & 3.2301 \\
\hline $\mathrm{A}_{2}$ & 1.7070 & 1.9150 & 2.1104 & 2.5538 \\
\hline $\mathrm{A}_{3}$ & -8.2671 & -9.1622 & -10.0360 & -11.2877 \\
\hline $\mathrm{A}_{4}$ & -7.8706 & -9.1201 & -10.9832 & -13.4950 \\
\hline$\sigma\left(\mathrm{cm}^{3} \cdot \mathrm{mol}^{-1}\right)$ & 0.0095 & 0.0103 & 0.0009 & 0.0017 \\
\hline \multicolumn{5}{|c|}{$[\mathrm{EMIM}][(\mathrm{EtO})(\mathrm{H}) \mathrm{PO} 2](1)+2-\operatorname{propanol}(2)$} \\
\hline $\mathrm{A}_{0}$ & -1.8404 & -2.0942 & -2.4739 & -2.8752 \\
\hline $\mathrm{A}_{1}$ & -1.1119 & -1.3754 & -1.5421 & -1.9691 \\
\hline $\mathrm{A}_{2}$ & 0.0195 & -0.0153 & 0.0572 & -0.0124 \\
\hline $\mathrm{A}_{3}$ & 1.0749 & 0.8081 & -0.8075 & 0.4902 \\
\hline $\mathrm{A}_{4}$ & -0.3085 & -0.3794 & 1.0762 & -1.3367 \\
\hline$\sigma\left(\mathrm{cm}^{3} \cdot \mathrm{mol}^{-1}\right)$ & 0.0014 & 0.0022 & 0.0010 & 0.0020 \\
\hline
\end{tabular}

$\mathrm{V}=\mathrm{V}^{\mathrm{E}}+\left(\mathrm{x}_{1} \mathrm{~V}_{1}^{0}+\mathrm{x}_{2} \mathrm{~V}_{2}^{0}\right)$

The molar volumes of the ionic liquid, $V_{1}^{0}$ and methanol or 2- propanol, $V_{2}^{0}$ were given by:

$\mathrm{V}_{1}^{0}=\mathrm{M}_{1} / \rho_{1}$

$\mathrm{V}_{2}^{0}=\mathrm{M}_{2} / \rho_{2}$

where $M_{1}, M_{2}, \rho_{1}$ and $\rho_{2}$ are respectively, the mole masses and the densities of ionic liquid and alcohols.

The introduction of Eqs. (3) and (4) in Eq. (5) leads to: $\mathrm{V}_{\varphi 1}=\mathrm{V}_{1}^{0}+\left(\mathrm{V}^{\mathrm{E}} / \mathrm{x}_{1}\right)$

$V_{\varphi 2}=V_{2}^{0}+\left(V^{E} / x_{2}\right)$

The apparent molar volumes of the ionic liquid are displayed in Figure 4 for the binary mixture $\left[\right.$ EMIM] $\left[(\mathrm{EtO})(\mathrm{H}) \mathrm{PO}_{2}\right](1)+$ methanol (2)], and Figure 5 for the binary mixture $[\mathrm{EMIM}]\left[(\mathrm{EtO})(\mathrm{H}) \mathrm{PO}_{2}\right](1)+2$-propanol (2)]. Figure 4 shows that the variations of the apparent molar volume of the ionic liquid at the investigated temperatures for the binary system [EMIM] $\left[(\mathrm{EtO})(\mathrm{H}) \mathrm{PO}_{2}\right](1)+$ methanol (2)] are more pronounced in diluted solution, indicating thus the presence of very strong interactions between the molecules of solute and solvents. In the ionic liquid rich region, the changes are neglected and the values of the apparent molar volume are basically the same, showing that in the concentrated solutions, the nature of interactions are strongly related to the ionic liquid of $[\mathrm{EMIM}]\left[(\mathrm{EtO})(\mathrm{H}) \mathrm{PO}_{2}\right.$. These findings are in line with conclusions resulted from the excess molar volumes. The binary system $\left[\right.$ EMIM] $\left[(\mathrm{EtO})(\mathrm{H}) \mathrm{PO}_{2}\right](1)+2$-propanol (2)] shows that the variations of the apparent molar volumes of the ionic liquid in diluted solutions are neglected at different temperatures. In the rich region, changes become more pronounced.

\subsection{Partial Molar Volume and Excess Partial Molar Volume}

In order to have more knowledge about interactions solute/solvent, the values of partial molar volumes of ionic liquid, $\mathrm{V}_{\mathrm{m}, 1}$ and methanol or 2-propanol, $\mathrm{V}_{\mathrm{m}, 2}$ in binary mixtures have been calculated using the following equations:

$V_{m, 1}=V_{m}^{E}+V_{1}^{0}+x_{2}\left(\frac{\partial V^{E}}{\partial x_{1}}\right)_{T, P}$

$V_{m, 2}=V_{m}^{E}+V_{2}^{0}-x_{1}\left(\frac{\partial V^{E}}{\partial x_{1}}\right)_{T, P}$

where $V_{1}^{0}$ and $V_{2}^{0}$ are the molar volumes of the pure components; $V_{m}^{E}$ is the excess molar volume of the mixtures; and $x_{1} ; x_{2}$ are the molar compositions of IL and methanol or 2-propanol respectively. 
The value of $\left(\frac{\partial V^{E}}{\partial x_{1}}\right)_{T, P}$ can be determined from "Eq. (2)" using the parameters $\mathrm{A}_{\mathrm{i}}$ of Table 4 .

The excess partial molar volumes of IL, $V_{m, 1}^{E}$, methanol or 2-propanol, and $V_{\mathrm{m}, 2}^{\mathrm{E}}$ have been calculated by the following equations:

$V_{m, 1}^{E}=\bar{V}_{1}-V_{1}^{0}$

$V_{m, 2}^{E}=\bar{V}_{2}-V_{2}^{0}$

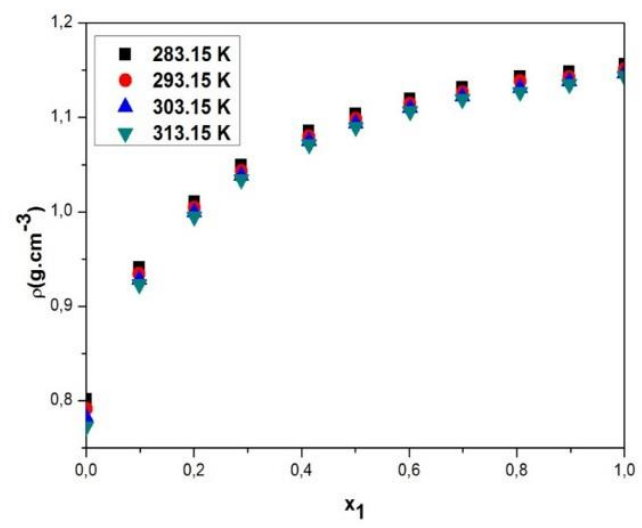

Figure 1. Densities ( $\rho)$ for the binary mixtures of $[$ EMIM] [(EtO $)\left(\mathrm{H}^{2} \mathrm{PO}_{2}\right](1)+$ methanol(2) as function of ionic liquid mole fraction $x_{1}$ at different temperatures.

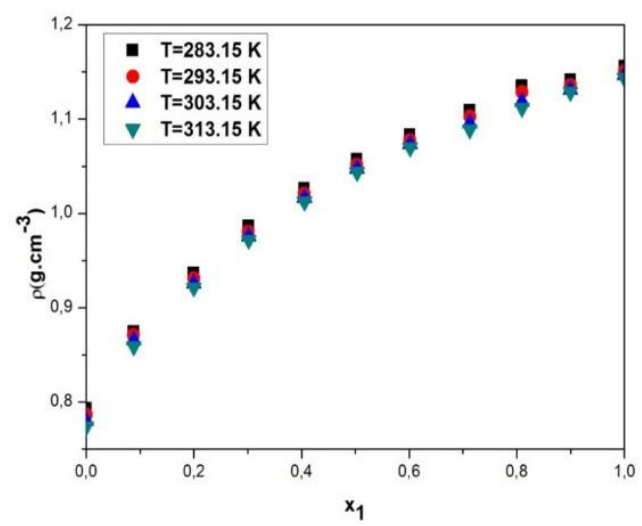

Figure 2. Densities ( $\rho)$ for the binary mixtures of $[\mathrm{EMIM}]\left[(\mathrm{EtO})(\mathrm{H}) \mathrm{PO}_{2}\right](1)+2$-propanol(2) as function of ionic liquid mole fraction $x_{1}$ at different temperatures.

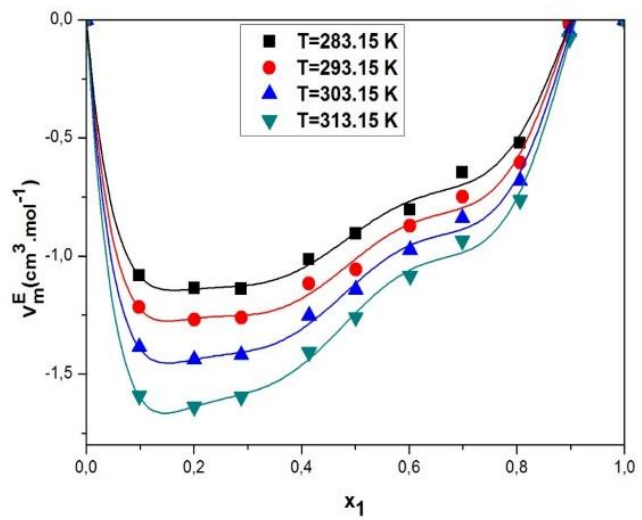

Figure 3. Variations of excess molar volume, $V_{m}^{E}$ with mole fraction, $x_{1}$ of $[E M I M]\left[(E t O)(H) P_{2}\right](1)+$ methanol(2) binary mixture at different temperatures. Solid curves were calculated from the Redlich-Kister equation.

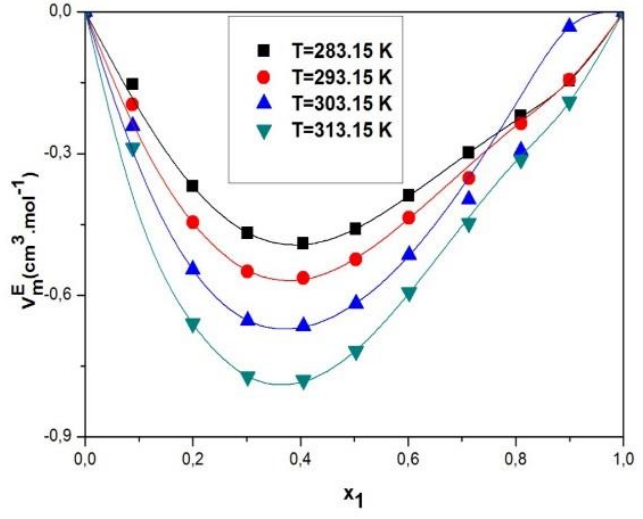

Figure 4. Variations of excess molar volume, $V_{m}^{E}$ with mole fraction, $x_{1}$ of $[E M I M]\left[(E t O)(H) P_{2}\right](1)+2$-propanol(2) binary mixture at different temperatures. . Solid curves were calculated from the Redlich-Kister equation.

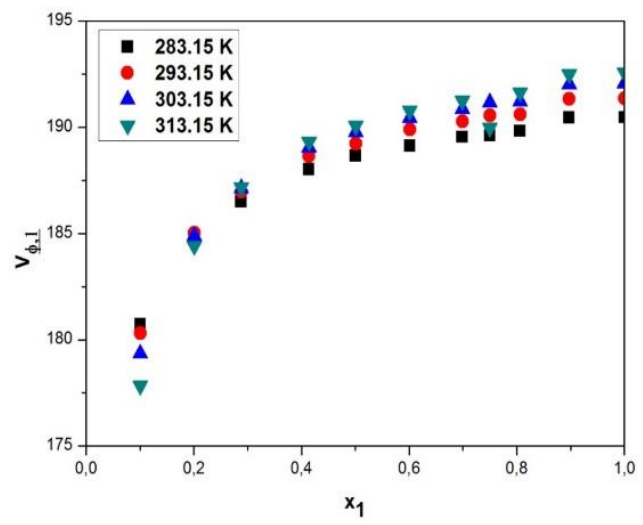

Figure 5. Apparent molar volume, $V_{\phi 1}$ of IL as a function of ionic liquid mole fraction in the binary mixture IL+methanol.

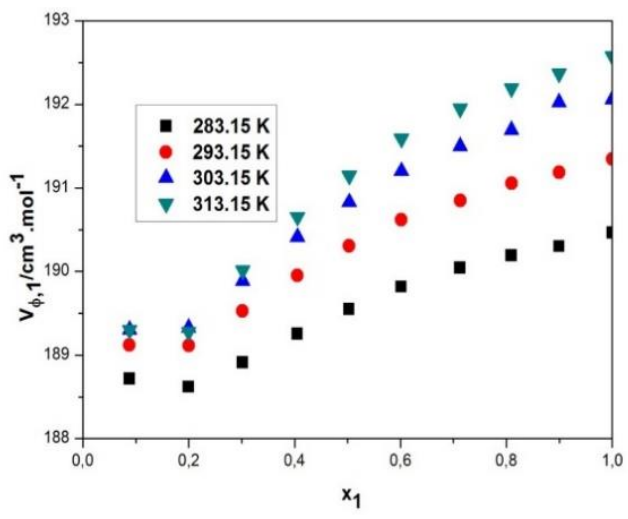

Figure 6. Apparent molar volume, $V_{\phi 1}$ of [EMIM][(EtO) $(\mathrm{H}) \mathrm{PO}_{2}$ as a function of ionic liquid mole fraction $x_{1}$ for the binary mixture $[\mathrm{EMIM}]\left[(\mathrm{EtO})(\mathrm{H}) \mathrm{PO}_{2}\right](1)+$ 2-propanol(2) at different temperatures. 


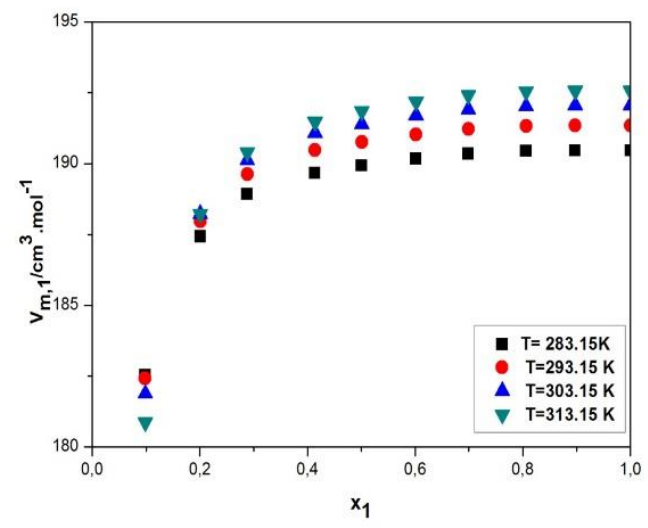

Figure 7. Plot of partial molar volumes $V_{m, 1}$ of [EMIM][(EtO) $\left(\mathrm{H}_{\mathrm{CPO}}\right.$ ] as a function of ionic liquid mole fraction $x_{1}$ for the binary mixture $[\mathrm{EMIM}]\left[(\mathrm{EtO})(\mathrm{H}) \mathrm{PO}_{2}\right](1)+$ methanol(2) at different temperatures.

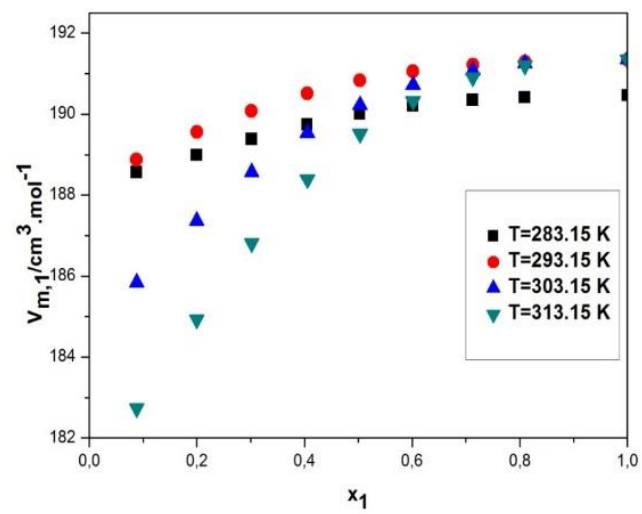

Figure 8. Plot of partial molar volumes $V_{m, 1}$ of [EMIM][(EtO) $(\mathrm{H}) \mathrm{PO}_{2}$ ] as a function of ionic liquid mole fraction $x_{1}$ for the binary mixture $[\mathrm{EMIM}]\left[(\mathrm{EtO})(\mathrm{H}) \mathrm{PO}_{2}\right](1)+$ 2-propanol(2) at different temperatures.

$V_{m, 1}=V_{m}^{E}+V_{1}^{0}+x_{2}\left(\frac{\partial V^{E}}{\partial x_{1}}\right)_{T, P}$

$V_{m, 2}=V_{m}^{E}+V_{2}^{0}-x_{1}\left(\frac{\partial V^{E}}{\partial x_{1}}\right)_{T, P}$

where $V_{1}^{0}$ and $V_{2}^{0}$ are the molar volumes of the pure components; $V_{m}^{E}$ is the excess molar volume of the mixtures; and $x_{1} ; x_{2}$ are the molar compositions of IL and methanol or 2-propanol, respectively. The value of $\left(\frac{\partial V^{E}}{\partial x_{1}}\right)_{T, P}$ can be determined from Eq. (2) using the parameters $A_{i}$ of Table 4.

The excess partial molar volumes of IL, $V_{m, 1}^{E}$, methanol or 2-propanol, and $V_{\mathrm{m}, 2}^{\mathrm{E}}$ have been calculated by the following equations:

$V_{m, 1}^{E}=\bar{V}_{1}-V_{1}^{0}$

$V_{m, 2}^{E}=\bar{V}_{2}-V_{2}^{0}$

The partial molar volumes of ionic liquid, methanol and 2-propanol in binary mixtures of [EMIM] $\left[(\mathrm{EtO})(\mathrm{H}) \mathrm{PO}_{2}\right](1)$ + methanol (2)] and [EMIM] $\left[(\mathrm{EtO})(\mathrm{H}) \mathrm{PO}_{2}\right](1)+2$-propanol (2)] are indicated in Table 5 displayed in Figures 5 and 6.

The values of $V_{m, 1}$ and $V_{m, 2}$ in binary mixtures are lower than their individual values of the pure state, which indicate that contraction of volume occurs in the mixtures of [EMIM] $\left[(\mathrm{EtO})(\mathrm{H}) \mathrm{PO}_{2}\right]$ with methanol and 2-propanol.

\subsection{Partial Molar Volume and Excess Partial Molar} Volume at Infinite Dilution

The partial molar volumes at infinite dilution for the ionic liquid, $V_{1}^{\infty}$ and methanol or 2-propanol $V_{2}^{\infty}$ are determined from the partial molar volumes when the values of $x_{1}$ and $x_{2}$ tend to zero according to the following equations:

$$
\begin{aligned}
& V_{1}^{\infty}=V_{1}^{0}+\sum_{i=0}^{n} A_{i}\left(x_{1} \rightarrow 0\right) \\
& V_{2}^{\infty}=V_{2}^{0}+\sum_{i=0}^{n} A_{i}(-1)^{i}\left(x_{2} \rightarrow 0\right)
\end{aligned}
$$

The excess partial molar volumes at infinite dilution of ionic liquid, $V_{1}^{E, \infty}$, methanol or 2-propanol, and $V_{2}^{\mathrm{E}, \infty}$ can be determined by using the values of the partial molar volumes at infinite dilution when $x_{1}$ and $x_{2}$ tend to zero, respectively as well as by rearrangement of "Eqs. (15) and (16)" :

$$
\begin{aligned}
& \left(V_{1}^{E}\right)^{\infty}=\sum_{i=0}^{n} A_{i} \\
& \left(V_{2}^{E}\right)^{\infty}=\sum_{i=0}^{n} A_{i}(-1)^{i}
\end{aligned}
$$

The values of $V_{i}^{E, \infty}$ indicated in table 6 for the two studied binary mixtures were found to be negative at all temperatures due to a volume contraction after addition of ionic liquid in an infinite volume of the corresponding alcohol. This contraction exhibits strong interactions between alcohol molecules and ionic liquid ions. Furthermore, the solvation interactions of alcohols-ionic liquid are stronger than the self-solvation interactions of like molecules [52]. Thus, the negative values of $V_{i}^{E, \infty}$ promote us to suggest that IL and alcohol molecules prefer to be surrounded by unlike molecules.

\subsection{Refractive Index}

The behavior of the refractive index of the studied mixtures was evaluated along with the determination of the refractive index deviations from experimental data according to the following equation:

$\Delta n_{D}=n_{D}-\left(x_{1} n_{D 1}+x_{2} n_{D 2}\right)$

where $x_{1}$ and $x_{2}$ are the mole fraction of components 1 and 2, $n_{D 1}, n_{D 2}$ and $n_{D}$, are, respectively the refractive indices of pure components and their mixtures.

The refractive index deviations of the binary mixtures $[\mathrm{EMIM}]\left[(\mathrm{EtO})(\mathrm{H}) \mathrm{PO}_{2}\right]$ (1) + methanol (2)] and $\left[\right.$ EMIM] [(EtO) $\left.(\mathrm{H}) \mathrm{PO}_{2}\right](1)+2$-propanol (2)] versus $x_{1}$ at $\mathrm{T}=293.15 \mathrm{~K}$ are plotted in Figures 9 and 10, respectively. $\Delta n_{D}$ presents a positive deviation from ideality over the whole composition range, whilst the positive deviations in refractive index deviation values indicate the presence of strong interactions in the mixtures, like ion-dipole interactions between Il ions and alcohols [50,54]. 
Table 5. Partial Molar Volume $V_{m, 1}$ for Ionic Liquid and $V_{m, 2}$ for Methanol or 2-propanol of the Two Binary Mixtures at Various Temperatures and at Under the Atmospheric Pressure.

\begin{tabular}{|c|c|c|c|c|}
\hline \multicolumn{5}{|c|}{ Temperature (K) } \\
\hline $\mathbf{X}_{1}$ & 283.15 & 293.15 & 303.15 & 313.15 \\
\hline \multicolumn{5}{|c|}{$[\mathrm{EMIM}]\left[(\mathrm{EtO})(\mathrm{H}) \mathrm{PO}_{2}\right](1)+$ methanol$(2)$} \\
\hline \multicolumn{5}{|c|}{$V_{m, 1}$ for ionic liquid $\left(\mathrm{cm}^{3} \cdot \mathrm{mol}^{-1}\right)$} \\
\hline 0.0983 & 182.5205 & 182.4227 & 181.8811 & 180.8652 \\
\hline 0.2007 & 187.4277 & 187.9613 & 188.2219 & 188.2177 \\
\hline 0.2879 & 188.9190 & 189.6366 & 190.1257 & 190.3961 \\
\hline 0.4138 & 189.6678 & 190.4738 & 191.0724 & 191.4677 \\
\hline 0.5006 & 189.9292 & 190.7649 & 191.4019 & 191.8423 \\
\hline 0.6015 & 190.1704 & 191.0318 & 191.7025 & 192.1839 \\
\hline 0.6988 & 190.3421 & 191.2191 & 191.9106 & 192.4163 \\
\hline 0.8059 & 190.4418 & 191.3247 & 192.0266 & 192.5415 \\
\hline 0.8973 & 190.4641 & 191.3468 & 192.0532 & 192.5699 \\
\hline
\end{tabular}

\begin{tabular}{|c|c|c|c|c|}
\hline \multicolumn{5}{|c|}{$\mathrm{V}_{m, 2}$ for methanol $\left(\mathrm{cm}^{3} \cdot \mathrm{mol}^{-1}\right)$} \\
\hline 0.0000 & 30.5269 & 32.0464 & 32.0203 & 36.1276 \\
\hline 0.0983 & 35.7194 & 37.1772 & 37.1235 & 40.5256 \\
\hline 0.2007 & 37.7247 & 39.1550 & 38.9874 & 41.7941 \\
\hline 0.2879 & 38.9614 & 40.2607 & 40.0881 & 42.1678 \\
\hline 0.4138 & 39.4616 & 40.6068 & 40.5328 & 42.1954 \\
\hline 0.6015 & 40.1659 & 41.1279 & 41.1910 & 42.4432 \\
\hline 0.6988 & 41.1716 & 41.9715 & 42.1660 & 43.1010 \\
\hline 0.8059 & 42.5855 & 43.2254 & 43.5632 & 44.2472 \\
\hline 0.8973 & 43.7131 & 44.2471 & 44.6869 & 45.2421 \\
\hline
\end{tabular}

$[\mathrm{EMIM}]\left[(\mathrm{EtO})(\mathrm{H}) \mathrm{PO}_{2}\right](1)+2-\operatorname{propanol}(2)$

\begin{tabular}{ccccc}
\multicolumn{5}{c}{$V_{m, 1}$ for ionic liquid $\left(\mathrm{cm}^{3} \cdot \mathrm{mol}^{-1}\right)$} \\
0.0878 & 188.8734 & 189.2862 & 189.0107 & 189.4685 \\
0.1998 & 189.4799 & 190.1545 & 189.8708 & 190.1331 \\
0.3016 & 189.8688 & 190.6481 & 190.5447 & 190.8204 \\
0.4052 & 190.1180 & 190.9463 & 191.4367 & 191.4288 \\
0.5027 & 190.2531 & 191.1053 & 191.7558 & 191.8682 \\
0.6014 & 190.3303 & 191.1972 & 191.9234 & 192.1827 \\
0.7126 & 190.3836 & 191.2609 & 192.1130 & 192.4078 \\
0.8094 & 190.4196 & 191.3018 & 192.1246 & 192.5177 \\
$\mathrm{~V}_{m, 2}$ for 2-propanol $\left(\mathrm{cm}^{3} . \mathrm{mol}^{-1}\right)$ & & \\
0.0878 & 74.0672 & 74.2037 & 73.7986 & 74.4029 \\
0.1998 & 74.5799 & 74.9637 & 74.5201 & 75.6668 \\
0.4052 & 75.2550 & 75.8438 & 75.8743 & 76.8404 \\
0.5027 & 75.5259 & 76.1740 & 76.4405 & 77.3147 \\
0.6014 & 75.7809 & 76.4882 & 76.9745 & 77.7783 \\
0.7126 & 76.0038 & 76.7897 & 77.6028 & 78.3113 \\
0.8094 & 76.0692 & 76.9414 & 78.2789 & 78.8203 \\
\hline \multicolumn{5}{c}{} \\
\hline
\end{tabular}

Table 6. Partial Molar Volume at Infinite Dilution $V_{m, i}^{\infty}$ and Excess Partial Molar Volume at Infinite Dilution $V_{m, i}^{E, \infty}$ for the Components of the Binary Mixtures $[E M I M]\left[(E t O)(H) P_{2}\right](1)+\quad$ methanol(2) and $[E M I M]\left[(E t O)(H) P_{2}\right](1)+$ 2-propanol(2) at Different Temperatures.

\begin{tabular}{|c|c|c|c|c|}
\hline $\mathbf{T} / \mathbf{K}$ & $\begin{array}{c}V_{m, 1}^{\infty} \\
/ \mathrm{cm}^{3} \cdot \mathrm{mol}^{-1}\end{array}$ & $\begin{array}{c}V_{\mathrm{m}, 1}^{\mathrm{E}, \infty} / \\
\mathrm{cm}^{3} \cdot \mathrm{mol}^{-1}\end{array}$ & $\begin{array}{c}V_{m, 2}^{\infty} \\
/ \mathrm{cm}^{3} \cdot \mathbf{m o l}^{-1}\end{array}$ & $\begin{array}{c}V_{\mathrm{m}, 2}^{\mathrm{E}, \infty} \\
/ \mathrm{cm}^{3} \cdot \mathrm{mol}^{-1}\end{array}$ \\
\hline 283.15 & 182.1138 & -3.8904 & 35.3105 & -16.2202 \\
\hline \multicolumn{5}{|c|}{$[\mathrm{EMIM}]\left[(\mathrm{EtO})(\mathrm{H}) \mathrm{PO}_{2}\right](1)+$ methanol$(2)$} \\
\hline 293.15 & 182.9942 & -4.7451 & 35.6537 & -18.1861 \\
\hline 303.15 & 181.7346 & -6.3986 & 36.4633 & -20.8818 \\
\hline 313.15 & 182.1581 & -8.2278 & 37.6647 & -24.3310 \\
\hline \multicolumn{5}{|c|}{$[\mathrm{EMIM}]\left[(\mathrm{EtO})(\mathrm{H}) \mathrm{PO}_{2}\right](1)+2-\operatorname{propanol}(2)$} \\
\hline 283.15 & 188.3710 & -2.0924 & 73.5653 & -2.1664 \\
\hline 293.15 & 189.4246 & -1.9216 & 73.3531 & -3.0562 \\
\hline 303.15 & 191.1249 & -0.9318 & 73.3556 & -3.6883 \\
\hline 313.15 & 192.2441 & -0.3325 & 74.3652 & -3.2903 \\
\hline
\end{tabular}

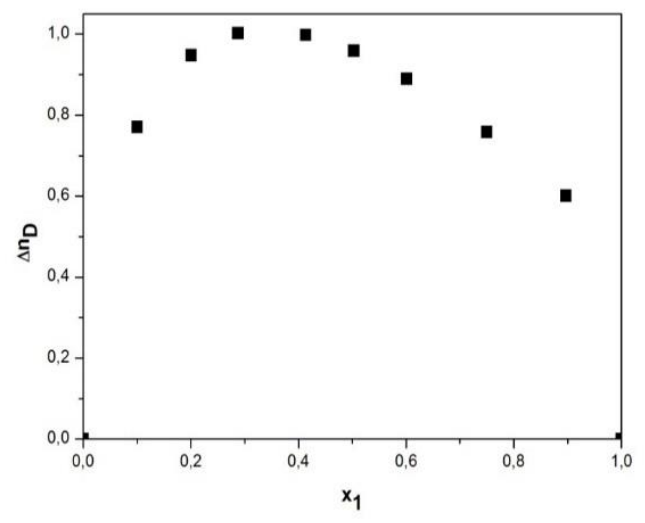

Figure 9. Refractive index deviation with mole fraction of the binary system $[\mathrm{EMIM}]\left[(\mathrm{EtO})(\mathrm{H}) \mathrm{PO}_{2}\right](1)+$ methanol(2)] at $293.15 \mathrm{~K}$.

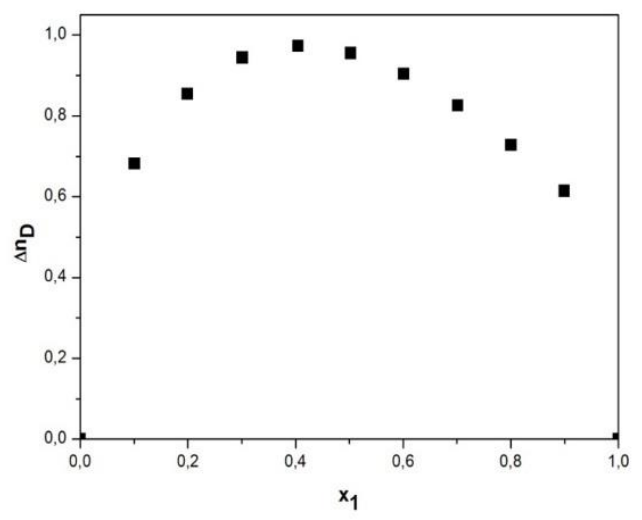

Figure 10. Refractive index deviation with mole fraction of the binary system $[\mathrm{EMIM}]\left[(\mathrm{EtO})(\mathrm{H}) \mathrm{PO}_{2}\right](1)+\quad 2$ propanol(2)] at $293.15 \mathrm{~K}$.

\section{Conclusions}

We have measured the refractive indices at $293.15 \mathrm{~K}$ and densities at $\mathrm{T}=(283.15,293.15,303.15$ and 313.15$) \mathrm{K}$ for the binary systems of 1-ethyl-3-methylimidazolium ethylphosphonate + methanol, or 2-propanol as a function of molecule composition under atmospheric pressure. The refractive index deviations of the investigated binary mixtures were determined. Based on the density data, the volumetric properties, including excess molar volumes, apparent molar volumes and partial and excess molar volumes at infinite dilution were deduced. The values of excess molar volumes were fitted to the Redlich-Kister equation. The $V_{m}^{E}$ values were found as negative over the whole range of composition and at all the investigated temperatures. Also, this negative deviation from the typical behavior indicates the presence of attractive interaction and or packing effect between the ionic liquid and alcohol molecules.

\section{References}

[1] R. Anantharaj, T. Banerjee, "COSMO-RS based Predictions for the Desulphurization of Diesel Oil using Ionic Liquids: Effect of Cation and Anion Combination," Fuel Process Technol., 92, 39, 2011.

[2] K. Kedra-Krolik, F. Mutelet, J-C. Moise, J-N. Jaubert, Deep Fuels Desulfurization and Denitrogenation using 1-butyl-3-methylimidazolium 
Trifluoromethanesulfonate," Energy Fuels., 25, 1559, 2011.

[3] K. Kedra-Krolik, M. Fabrice, J.-N. Jaubert, "Extraction of Thiophene or Pyridine from n-Heptane using Ionic Liquids Gasoline and Diesel Desulfurization," Ind. Eng. Chem. Res., 50, 2296-2306, 2011.

[4] A. Seeberger, A. Jess, "Desulfurization of Diesel Oil by Selective Oxidation and Extraction of Sulfur Compounds by Ionic Liquids - A Contribution to a Competitive Process Design," Green Chem., 12, 602$608,2010$.

[5] F. Mutelet, P. Carré, A. Skrzypczak, "Study of Interaction between Organic Compounds and Mono or Dicationic Oxygenated Ionic Liquids using Gas Chromatography," Fluid Phase equilibria., 387, 59-72, 2015.

[6] F. Mutelet, A.-L. Revelli, J.-N. Jaubert, L.M. Sprunger, W.E.Jr. Acree, G.A. Baker, "Partition Coefficients of Organic Compounds in New Imidazolium and Tetralkylammonium based Ionic Liquids using Inverse Gas Chromatography," J. Chem. Eng. Data., 55, 234 242, 2009.

[7] S. Keskin, D. Kayrak-Talay, U. Akman, O.A. Hortacsu, "A Review of Ionic Liquids towards Supercritical Fluid Applications," J. Supercrit. Fluids., 43, 150-180, 2007.

[8] N. Deenadayalu, I. Bahadur, T. Hofman, "Volumetric Properties for (Ionic liquid + Methanol or Ethanol or 1Propanol + Nitromethane) at $298.15 \mathrm{k}$ and Atmospheric Pressure," J. Chem. Eng. Dat., 56, 1682-1686, 2011.

[9] A. Kokorin, "Ionic Liquids: Applications and Perspectives, ” In Tech, Croatia, 2011.

[10] F. Mutelet, J.-N. Jaubert, "Measurement of Activity Coefficients at Infinite Dilution in 1-hexadecyl-3methylimidazolium tetrafluoroborate Ionic Liquid," $J$. Chem. Thermodyn., 39, 1144-1150, 2007.

[11] P. Wasserscheid, T. Welton, "Ionic Liquids in Synthesis", Wiley-VCH, 2003.

[12] A.L. Revelli, F. Mutelet, M. Turmine, R. Solimando, J.N. Jaubert, "Activity Coefficients at Infinite Dilution of Organic Compounds in 1-butyl-3-methylimidazolium tetrafluoroborate using Inverse Gas Chromatograph," $J$. Chem. Eng. Data., 54, 90-101, 2008.

[13] A.B. Pereiro, J.M.M. Araújo, J.M.S.S. Esperança, I.M. Marrucho, L.P.N. Rebelo, "Ionic Liquids in Separations of Azeotropic Systems - A Review," J. Chem. Thermodyn., 46, 2-28, 2012.

[14] A. Heintz, D.V. Kulikov, S.P. Verevkin, "Thermodynamic Properties of Mixtures Containing Ionic Liquids. Activity Coefficients at Infinite Dilution of Polar Solutes in 4-methyl- $N$-butyl-pyridinium tetrafluoroborate using Gas-Liquid Chromatography," J. Chem. Thermodyn., 34, 1314-1347, 2002.
[15] T. M. Letcher, N. Deenadayalu, B. Soko, D. Ramjugernath, A. Nevines, P.K Naicker, "Activity Coefficients at Infinite Dilution of Organic Solutes in 1hexyl-3-methylimidazolium hexafluorophosphate from gas-liquid chromatography," J. Chem. Eng. Data., 48, 708-711, 2003.

[16] T.V. Vasiltsova, S.P. Verevkin, E. Bich, A. Heintz, R. Bogel-Lukasisk, U. Domanska, "Thermodynamic Properties of Mixtures Containing Ionic Liquids. Activity Coefficients of Aldehydes and Ketones in 1methyl-3-ethyl-imidazolium bis (trifluoromethylsulphonyl) imide using the Transpiration Method," $J$. Chem. Eng. Data., 50, 142-148, 2005.

[17] T.M. Letcher, B. Soko, P. Reddy, N. Deenadayalu, "Determination of Activity Coefficients at Infinite Dilution of Solutes in the Ionic Liquid 1-hexyl-3methylimidazolium tetrafluoroborate using Gas-Liquid Chromatography at the Temperatures $298.15 \mathrm{~K}$ and 323.15 K,". J. Chem. Eng. Data., 48, 1587-159, 2003.

[18] M. Radhamma, P. Venkatesu, M.V.P. Rao, M.J. Lee, H.M. Lin, "Excess Molar Volumes and Ultrasonic Studies of Dimethylsulphoxide with Ketones at $\mathrm{T}=$ 303.15 K," J. Chem. Thermodyn., 40, 492-497, 2008.

[19] R.M. Pires, H.F. Costa, A.G.M. Ferreira, I.M.A. Fonseca, "Viscosity and Density of water + ethyl acetate + ethanol Mixtures at 298.15 and $318.15 \mathrm{k}$ and Atmospheric Pressure," J. Chem. Eng. Data., 52, 12401245, 2007.

[20] F. Mutelet, A.-L. Revelli, J.-N. Jaubert, L.M. Sprunger, W.E.Jr. Acree, G.A. Baker, "Partition Coefficients of Organic Compounds in New Imidazolium and Tetralkylammonium based Ionic Liquids using Inverse Gas Chromatography," J.Chem. Eng. Data., 55, 234 242, 2010.

[21] A.-L. Revelli, F. Mutelet, J-N. Jaubert, M. GarciaMartinez, L.M. Sprunger, W.E.Jr. Acree, J. A. Baker, "Study of ether-alcohol-, or cyano-Functionalized Ionic Liquids using Inverse Gas Chromatography," J. Chem. Eng. Data., 55, 2434-2443, 2010.

[22] A-L. Revelli, F. Mutelet, J.-N. Jaubert, "Prediction of Partition Coefficients of Organic Compounds in Ionic Liquids," Ind. Eng. Chem. Res., 49, 3883-3892, 2010.

[23] T.M. Letcher, U. Domanska, M. Marciniak, A. Marciniak, "Activity Coefficients at Infinite Dilution Measurements for Organic Solutes in the ionic liquid 1butyl-3-methyl-imidazolium 2-(2-methoxyethoxy) ethyl sulfate using Gas Liquid Chromatography at $T=$ (298.15, 303.15, and 308.15) K," J. Chem. Thermody., 37, 587-593, 2005.

[24] I. Bahadur, B.B. Govender, K. Osman, M.D. WilliamsWynn Nelson, W.M.P. Naidoo, D. Ramjugernat, "Measurement of Activity Coefficients at Infinite Dilution of Organic Solutes in the Ionic Liquid 1-ethyl3-methylimidazolium 2-(2-methoxyethoxy) ethylsulfate 
at $\mathrm{T}=(308.15,313.15,323.15$ and 333.15$) \mathrm{K}$ using Gas + Liquid Chromatography," J. Chem. Thermodyn., 70, 245-252, 2005.

[25] U. Domanska, G.G. Redhi, A. Marciniak, "Activity Coefficients at Infinite Dilution Measurements for Organic Solutes and Water in The Ionic Liquid 1-butyl1-methylpyrrolidinium trifluoromethanesulfonate using GLC," Fluid Phase Equilib., 278, 97-102, 2009.

[26] U. Domanska, M.J. Laskowska, "Effect of Temperature and Composition on the Density and Viscosity of Binary Mixtures of Ionic Liquid with Alcohols," J. Chem. Thermodyn., 41, 645-650, 2009.

[27] U. Domanska, A. Marciniak, "Measurements of Activity Coefficients at Infinite Dilution of Aromatic and Aliphatic Hydrocarbons, Alcohols and Water in New Ionic Liquid [EMIM][SCN] using GLC," $J$. Chem. Thermodyn., 40, 860-866, 2008.

[28] J.S. Dickmann, J.C. Hassler, E. Kiran, "Modeling of the Volumetric Properties and Estimation of the Solubility Parameters of Ionic Liquid + Ethanol Mixtures with the Sanchez-Lacombe and Simha-Somcynsky Equations of State: [EMIM]Ac+ethanol and [EMIM]Cl+ethanol mixtures," J. Supercrit. Fluids., 98, 86-101, 2015.

[29] D. Matkowska, T. Hofman, "Volumetric Properties of the Ionic Liquids: [C6mim][MeSO4], [C6mim][EtSO4], [C4mim][EtSO4] and their Mixtures with Methanol or Ethanol," J. Mol. Liq., 177, 301-305, 2013.

[30] N. Calvar, E.J. Gonzalez, A. Dominguez, E.A. Macedo, "Acoustic, Volumetric and Osmotic Properties of Binary Mixtures Containing the Ionic Liquid 1-butyl-3methylimidazolium dicyanamide Mixed with Primary and Secondary Alcohols," J. Chem. Thermodyn., 50, 19-29, 2012.

[31] Y. Deng, P. Husson, J. Jacquemin, T.G.A. Youngs, V.L. Kett, C. Hardacre, M.F.C. Gomes, "Volumetric Properties and Enthalpies of Solution of Alcohols $\mathrm{CkH} 2 \mathrm{k}+1 \mathrm{OH} \quad(\mathrm{k}=1, \quad 2, \quad 6) \quad$ in 1-methyl-3alkylimidazolium bis(trifluoromethylsulfonyl)imide $\{[\mathrm{C} 1 \mathrm{CnIm}][\mathrm{NTf} 2] \mathrm{n}=2,4,6,8,10\}$ ionic liquids," $J$. Chem. Thermodyn., 43, 1708-1718, 2011.

[32] N. Deenadayalu, I. Bahadur, T. Hofman, "Volumetric Properties for (Ionic liquid + methanol or ethanol or 1propanol + nitromethane) at $298.15 \mathrm{k}$ and atmospheric pressure," J. Chem. Eng. Data., 56, 1682-1686, 2011.

[33] U. Domanska, A. Pobudkowska, A. Wisniewska, "Refractive Indices, Density and Derivative Properties of Binary Mixtures Hydroxylic Solvents with Ionic Liquid (1-ethyl-3-methyl imidazolium ethylsulfate and 1-methyl-3-mmethylimidazolim methylsulfate from 298.15 K to 318.15 K,' J. Solution Chem., 35, 311-334, 2011.

[34] E.R.E. Hassan, F. Mutelet, S. Pontvianne, J.C. Moise, "Studies on the Dissolution of Glucose in Ionic Liquids and Extraction Using the Antisolvent Method," Environ. Sci. Technol., 47(6), 2809-2816, 2013.

[35] A. Ayad, F. Mutelet, E.S. Abumandour, A. Negadi.; "Activity Coefficients at Infinite Dilution of Organic Solutes in Methylphosphonate based Ionic Liquids using Gas-Liquid Chromatography," J. Chem. Thermodyn., 86, 116-122, 2015.

[36] F. Mutelet, J.-C. Moise, A. Skrzypczak, "Evaluation of the Performance of Trigeminal Tricationic Ionic Liquids for Separation Problems," J. Chem. Eng. Data., 57, 918927, 2011.

[37] F. Mutelet, J.N. Jaubert, "Accurate Measurements of Thermodynamic Properties of Solutes in Ionic Liquids using Inverse Gas Chromatography," J. Chromatogr. A., 1102, 256-267, 2006.

[38] U. Domanska, E.V. Lukoshko, M. Krolikowski, "Separation of Thiophene from Heptane with Ionic Liquids," J. Chem. Thermodyn., 61, 126-131, 2013.

[39] A. Marciniak, "Influence of Cation and Anion Structure of the Ionic Liquid on Extraction Processes based on Activity Coefficients at Infinite Dilution. A Review," Fluid Phase Equilib., 294, 213-233, 2010.

[40] F. Allal, F. Mutelet, A. Dahmani, B. Saidat, "Measurements of Activity Coefficients at Infinite Dilution of Organic Solutes in the Ionic Liquid 1-ethyl3-methylimidazolium ethylphosphonate [EMIM][(EtO)(H)PO $\left.\mathrm{PO}_{2}\right]$ using Gas-Liquid Chromatography," J. Mol. Liq., 220, 243-247, 2016.

[41] K-S. Kim, B.H. Park, "Volumetric Properties of Solutions of Choline Chloride + Glycerol Deep Eutectic Solvent with Water, Methanol, Ethanol, or Isopropanol," J. Mol. Liq., 254, 272-279, 2018.

[42] Q. Yang, H. Zhang, B. Su, Y. Yang, Q. Ren, H. Xing, "Volumetric Properties of Binary Mixtures of 1-butyl3-methylimidazolium chloride + water or hydrophilic Solvents at Different Temperatures," J. Chem. Eng. Data., 55, 1750-1754, 2010.

[43] G. Gonfa, M.A. Bustam, N. Muhammad, S. Ullah, "Density and Excess Molar Volume of Binary Mixture of Thiocyanate based Ionic Liquids and Methanol at temperatures 293.15-323.15 K". J. Mol. Liq., 211, 734$741,2015$.

[44] C. Yang, H. Lai, Z. Liu, P. Ma, "Densities and Viscosities of Diethyl Carbonate + Toluene, + Methanol, and + 2-Propanol from (293.15 to 363.15) K," J. Chem. Eng. Data., 51, 584-589, 2006.

[45] F.M. Pang, C.E. Seng, T.T. Teng, M.H. Ibrahim, "Densities and Viscosities of Aqueous Solutions of 1Propanol and 2-Propanol at Temperatures from 293.15 K to 333.15 K," J. Mol. Liq., 136, 71-78, 2007.

[46] O. Ridlich, A.T. Kister, "Algebraic Representation of Thermodynamic Properties and the Classification of Solutions," Ind. Eng. Chem., 40, 345-348, 1948. 
[47] E. Vercher, A.V. Orchilles, P.J. Miguel, A. MartınezAndreu, "Volumetric and Ultrasonic Studies of 1-ethyl3-methylimidazolium trifluoromethanesulfonate Ionic Liquid with Methanol, Ethanol, 1-Propanol, and Water at Several Temperatures," J. Chem. Eng. Data., 52, 1468-1482, 2007.

[48] Y.-H. Gong, C. Shen, Y.-Z.Lu, H. Meng, C-X. Li, "Viscosity and Density Measurements for Six Binary Mixtures of Water, Methanol or Ethanol with an Ionic Liquid ([bmim][dmp] or [emim][dmp]) at Atmospheric Pressure in the Temperature Range of (293.15 to 333.15) K," J. Chem. Eng. Data., 57, 33-39, 2012.

[49] Y. Zhong, H. Wang, K. Diao, "Densities and Excess Volumes of Binary Mixtures of the Ionic Liquid 1-butyl3-methylimidazolium hexafluorophosphate with Aromatic Compound at $\mathrm{T}=(298.15$ to 313.15$) \mathrm{K}$," $J$. Chem. Thermodyn., 39, 291-296, 2007.

[50] M.S. Sandhya, C.N. Rao, K. Sivakumar, P. Bhanuprakash, P. Venkateswarlu, "Effect of Temperature and Alkyl Chain Lengh on Molecular Interactions in the Binary Mixtures of 1-ethyl- 3_methylimidazolium methyl sulphate with 1-alkanols (C3-C6)," J. Mol. Liq., 222, 981-987, 2016.

[51] E. Vercher, A.V. Orchillés, F.J. Liopez, V. GonzalezAlfaro, A. Martinez-Audren, "Ultrasonic and Volumetric Properties of 1-ethyl-3-methylimidazolium trifluoromethanesulfonate ionic liquid with 2-propanol or tetrahydrofuran at Several Temperatures," J. Chem. Eng. Data., 56, 4633-4642, 2011.

[52] S. Belic, N. Zec, M. Vranes, L. Grbovic, S. PodunavacKuzmanovic, S. Kovacevic, S. Gadsuric, "Nature of the Interactions in Binary Mixtures of 1-butyl-3ethylimidazolium bromide Ionic Liquid with Methanol and Ethanol," J. Mol. Liq., 229, 212-216, 2017.

[53] A. Pineiro, P. Brocos, A. Amigo, M. Pintos, "Prediction of Excess Volumes and Excess Surface Tensions from Experimental Refractive Indices," Phys. Chem. Liq., 38, 251-260, 2000.

[54] P. Brocos, A. Pinerio, R. Bravo, A. Amigo, "Refractive Indices, Molar Volumes and Molar Refractions of Binary Liquid Mixtures: Concepts and Correlations," Phys. Chem. Chem. Phys., 5, 550-557, 2003. 